\title{
Consumer Surplus Under Uncertainty: An Application to Dam-Reservoir Projects
}

\author{
JAMES QUIRK
}

\author{
California Institute of Technology, Pasadena
}

\begin{abstract}
The use of cost-benefit analysis to evaluate the net welfare payoffs from water projects has now been an established practice for many years. One of the interesting aspects of such cost-benefit studies is that water projects involve an uncertain flow of costs and benefits, arising from the stochastic nature of streamflows. Hence a basic problem for the cost-benefit analyst is that of incorporating this uncertainty into his measures of costs and benefits. In the present paper we examine the problem of computing an appropriate consumer surplus measure to evaluate water project benefits under uncertainty. Detailed treatment is given to the case in which a complete set of contingent claim markets exists in the economy as well as to the case of a spot market economy. The consumer surplus measure applicable to the contingent claim economy is a simple generalization of the measure that applies to a world of certainty, but in the case of a spot market economy there is an unobserved component of consumer benefits that limits the applicability of the usual consumer surplus measure.
\end{abstract}

\section{INTRODUCTION}

The use of cost-benefit analysis to evaluate the net welfare payoffs from water projects has now been an established practice for many years. One of the interesting aspects of such cost-benefit studies is that water projects involve an uncertain flow of costs and benefits, arising from the stochastic nature of streamflows. Hence a basic problem for the cost-benefit analyst is that of incorporating this uncertainty into his measures of costs and benefits. In the present paper, we examine the problem of computing an appropriate consumer surplus measure to evaluate water project benefits under uncertainty. Detailed treatment is given to the case in which a complete set of contingent claim markets exists in the economy, as well as to the case of a spot market economy. The consumer surplus measure applicable to the contingent claim economy is a simple generalization of the measure that applies to a world of certainty, but in the case of a spot market economy, there is an unobserved component of consumer benefits that limits the applicability of the usual consumer surplus measure.

\section{A Contingent Claim Water Economy}

To keep the notational clutter to a minimum, we consider the case of a world in which there are two consumer goods, $y$ and $z$, where $y$ denotes the consumption of water and $z$ is a nonwater good (say, a composite commodity). Again for simplicity, we consider a modified pure trade world in which there is no production of $z$; consumption of $z$ equals the endowment of consumers, while water availability is determined by random streamflows and storage capacity. The only uncertainty in the first model we consider is uncertainty as to streamflows. Let $\pi_{j t}$ denote the probability of streamflow $j$ in period $t$. There are assumed to be $J$ possible streamflow levels in each period and $T$ periods. We take the probability distribution over streamflows to be "objective," since historical streamflows are tabled for most major rivers and their tributaries, and we assume that water users are aware of these data and make use of them in their decision making. Again, mainly for notational convenience, we take the probability distribution over streamflows to be stationary with respect to

Copyright 1985 by the American Geophysical Union.

Paper number 5 W0388.

0043-1397/85/005W-0388\$05.00 time, and intertemporal independence is assumed as well. Thus the joint probability of the sequence of streamflows $\left(x_{j_{1}}\right.$, $x_{j_{2}}, \cdots, x_{j_{t}}$ ) is given by $\pi_{j_{1}} \pi_{j_{2}} \cdots \pi_{j_{i}}$.

As a matter of notation, let

$$
x\left(j_{1} \rightarrow j_{t}\right)=\left(x_{j_{1}}, \cdots, x_{j_{t}}\right)
$$

We first examine the cost-benefit problem in the context of an Arrow-Debrew [Arrow, 1964] type world in which there is a complete set of contingent claim markets all of which open at time 0 . Consumers make binding commitments to consumption over the $T$ period horizon through purchases and sales of contingent claims to the goods $y$ and $z$ at time 0 ; all market transactions occur in the period 0 contingent claim markets. Randomness enters the picture because of stochastic streamflows; there is no randomness emanating from the consumption side or from the supply side with respect to commodity $z$.

Let $y_{j_{1} \cdots j_{t}}{ }^{i}$ denote the number of contingent claim contracts acquired by consumer $i$, satisfying the property that each claim pays one unit of good $y$ in period $t$ if the streamflow sequence $x\left(j_{1} \rightarrow j_{t}\right)$ occurs. Similarly, let $p_{j_{1} \cdots j_{t}}$ denote the price of such a contingent claim contract. $z_{j_{1} \cdots j_{t}}{ }^{t}$ is the number of contingent claims to $z$ acquired by $i$, satisfying the property that each claim pays one unit of good $z$ in period $t$ if the streamflow $x\left(j_{1} \rightarrow j_{t}\right)$ occurs, with $q_{j_{1} \cdots j_{t}}$ being the price of such a contract. Note also that if the streamflow sequence $x\left(j_{1} \rightarrow j_{t}\right)$ occurs, then consumption by consumer $i$ in period $t$ is the vector $\left(y_{j_{1} \cdots j_{t}}{ }^{i}, z_{j_{1} \cdots j_{t}}{ }^{i}\right)$, because of the absence of spot markets in the periods following period 0 ; that is, purchases of contingent claim contracts are binding commitments to consumption. (This is the same assumption made by Arrow [1964] in his treatment of a contingent claim economy. In a variant of this model, Arrow also considers a "security market" world in which spot markets exist but future spot prices are known with certainty at time 0 .)

To simplify notation, let $\Omega_{\imath}$ denote the index over streamflows $x\left(j_{1} \rightarrow j_{t}\right)$ commencing at time 1 and terminating at time $t$. Let

$$
\Omega=\bigcup_{t=1}^{T} \Omega_{t}
$$

denote the set of all index sets over streamflow sequences, ranging from one to $T$ period sequences. Then $\Omega_{t}$ is also the 
index set over consumptions in period $t$ and over prices $(p, q)$ of contingent claim contracts to $t$ th period consumption.

Given the usual separability assumptions concerning preferences, the decision problem for consumer $i$ reduces to the following:

$$
\max _{\left(\boldsymbol{y}^{i}, z^{i}\right)} E U^{i}=\sum_{t=1}^{T} \beta_{i}{ }^{t} \sum_{r \in \Omega_{t}} \pi_{r} u_{t}^{i}\left(y_{r}{ }^{i}, z_{r}{ }^{i}\right)
$$

subject to

$$
W^{i}(T)=\sum_{t=1}^{T} \delta^{t} \sum_{r \in \Omega_{t}}\left(M_{r}^{i}-p_{r} y_{r}{ }^{i}-q_{r} z_{r}{ }^{i}\right)=0
$$

where $\left(y^{i}, z^{i}\right)$ is the matrix of contingent claim purchases by consumer $i, \beta_{i}$ is consumer $i$ 's personal discount factor, $\delta=[1 /(1+i)]$, where $i$ is the market rate of interest, $M_{r}{ }^{i}$ is income for consumer $i$, and $W^{i}(T)$ is consumer $i$ 's wealth at time $T$. We take $M_{r}{ }^{i}=N_{r}{ }^{i}+p_{r} \dot{y}_{r}{ }^{i}+q_{r} \dot{z}_{r}{ }^{i}$, where $\dot{y}_{r}{ }^{i}$ and $\dot{z}_{r}{ }^{i}$ are the endowments of consumer $i$ of $y$ and $z$ at time $t$ if the stream flow sequence $r$ occurs, and $N_{r}{ }^{i}$ is $i$ 's share of water profits given $r$. In what follows we assume that $\dot{y}_{r}{ }^{i}=0$ for all $i$, $r$.

This gives rise to the usual first-order conditions, assuming a regular interior maximum, that is,

$$
\begin{aligned}
\frac{\partial E U^{i}}{\partial y_{r}{ }^{i}}-\lambda \frac{\partial W^{i}(T)}{\partial y_{r}{ }^{i}} & =0 \\
\frac{\partial E U^{i}}{\partial z_{r}{ }^{i}}-\lambda \frac{\partial W^{i}(T)}{\partial z_{r}{ }^{i}} & =0 \\
W^{i}(T) & =0
\end{aligned}
$$

Given the structure of markets outlined above, we are interested in constructing a measure, in the form of consumers' surplus, of the benefits associated with controlling a river. In particular, we are interested in a measure of the benefits from a change from a completely uncontrolled river to one with a dam-reservoir complex controlling flows, with a reservoir storage capacity of $S^{*}$ units (acre feet, milliliters) of water, where $S^{*}$ is some given constant. To finesse the well-known aggregation problems plaguing consumers' surplus, we will instead calculate consumer's surplus for one individual, say consumer $i$. Then the relevant measure of benefits for the consumer is presumably the amount of discounted income that consumer $i$ is willing to give up to be indifferent between facing a controlled river with $S^{*}$ units of storage capacity and facing an uncontrolled river. Thus we are dealing with the compensated demand curve(s) for $y^{i}$, along which $E U^{i}$ is a constant. In the usual partial equilibrium approach, we assume that the prices

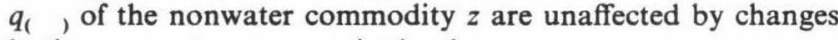
in the water storage capacity levels.

To simplify the notation, we will drop the superscript identifying the individual where there is no problem of ambiguity. Let DPV denote the discounted present value of income for consumer $i$. Then DPV is given by

$$
\mathrm{DPV}=\sum_{t=1}^{T} \delta^{t} \sum_{s \in \Omega_{t}} M_{s}
$$

Since $W(T)=0$ is a binding constraint that holds for all values of $S$, then, given a change $d S$ in the reservoir storage level, $d W(T)=0$. Taking $q_{r}$ constant for all $r$, we have

$d \mathrm{DPV}=(-) \sum_{r \in \Omega}\left[\frac{\partial W(T)}{\partial p_{r}}+\sum_{s \in \Omega}\left(\frac{\partial W(T)}{\partial y_{s}} \frac{\partial y_{s}}{\partial p_{r}}\right.\right.$

$$
\left.\left.+\frac{\partial W(T)}{\partial z_{s}} \frac{\partial z_{s}}{\partial p_{r}}\right)\right]\left(\frac{d p_{r}}{d S}\right) d S
$$

Along a compensated demand curve, $d \mathrm{EU}=0$; thus

$$
d E U=\sum_{r \in \Omega}\left[\sum_{s \in \Omega} \frac{\partial E U}{\partial y_{s}} \frac{\partial y_{s}}{\partial p_{r}}+\frac{\partial E U}{\partial z_{s}} \frac{\partial z_{s}}{\partial p_{r}}\right]\left(\frac{d p_{r}}{d S}\right) d S=0
$$

By the first-order conditions (2),

$$
\frac{\partial E U}{\partial y_{s}}=\lambda \frac{\partial W(T)}{\partial y_{s}} \quad \frac{\partial E U}{\partial z_{s}}=\lambda \frac{\partial W(T)}{\partial z_{s}}
$$

Given nonsatiation, $\lambda>0$, and thus (4) reduces to

$$
d \mathrm{DPV}=-\sum_{r \in \Omega}\left(\frac{\partial W(T)}{\partial p_{r}}\right)\left(\frac{d p_{r}}{d S}\right) d S=\sum_{t=1}^{T} \delta^{t} \sum_{r \in \Omega_{t}} y_{r}{ }^{c}\left(\frac{d p_{r}}{d S}\right) d S
$$

where $y_{r}{ }^{c}$ is the compensated demand curve for $y_{r}$.

Thus the consumer surplus measure relevant for the comparison between an uncontrolled river and one with a reservoir capacity of $S^{*}$ units is given by

$$
\mathrm{CS}=(-) \sum_{t=1}^{T} \delta^{t} \sum_{r \in \Omega_{t}} \int_{0}^{S *} y_{r} c\left(\frac{d p_{r}}{d S}\right) d S
$$

In the special case where $y_{r}{ }^{c}$ depends only on $p_{r}$ and where $S$ affects only one price $p_{r}$, then by a change of variables we end up with the usual consumer's surplus area computed from the compensated demand curve for $y_{r}$, but clearly this is a case with no practical significance for the evaluation of the typical water project. In any case, it is clear that the consumer's surplus measure calculated in (8) is of precisely the same form as the corresponding consumer's surplus measure for the certainty case. (For example, see Samuelson [1947] for a classic treatment of consumer surplus under certainty.) The major difference is that the contingent claim version incorporates the alternative possible streamflows indexed by the set $\Omega$. As Rogerson [1979] has noted in a different context, this correspondence reflects in part at least the fact that uncertainty is assumed to enter the picture in our model only from the supply side of the market.

Turning to the supply side of the market, assume that a public agency is charged with the task of operating the damreservoir complex, using the rule of maximizing expected profits taking prices (of contingent claims) as parameters. In analyzing the decision making process of the agency, timing of inflows and releases is of importwnce. We assume that in any period, inflows and releases occur at the end of the period, just before the reservoir level is measured. The $t$ th period begins at time $t-1$ and ends at time $t$.

Let $S_{j_{1} \cdots j_{t}}$ be the amount of water stored in the reservoir at time $t$, given the sequence of streamflows $x\left(j_{1} \rightarrow j_{t}\right)$ and given an optimal (expected profit maximizing) release policy. $y_{j_{1} \cdots j_{t}}{ }^{*}$ is the optimal level of releases in period $t$, given the streamflow sequence $x\left(j_{1} \rightarrow j_{t}\right)$, and $R_{j_{1} \cdots j_{t}}$ is the amount of water available for release in the $t$ th period, being measured near the end of that period, after inflows are known but before releases have occurred.

Then we have the following accounting identities:

$$
S_{r}=(1-\alpha) S_{s}+x_{j_{t}}-y_{r}{ }^{*} \quad s \in \Omega_{t-1} \quad r=\left(s, j_{t}\right)
$$

where $\alpha$ is the percentage loss in reservoir stocks due to evaporation;

$$
R_{r}=(1-\alpha) S_{s}+x_{j_{t}} \quad s \in \Omega_{t-1} \quad r=\left(s, j_{t}\right)
$$


so that

$$
R_{r}=(1-\alpha)\left[R_{s}-y_{s}^{*}\right]+x_{j_{t}} \quad s \in \Omega_{t-1} \quad r=\left(s, j_{t}\right)
$$

The dam-reservoir operator then chooses a sequence of releases to maximize expected profits. Let $r=\left(j_{1}, \cdots, j_{t}\right) \in \Omega_{t}$, and let $x(r) \equiv x\left(j_{1} \rightarrow j_{t}\right)$. Then at time $t$, when the streamflow sequence $x(r)$ is already known to have occurred, the operator chooses the release $y_{r}{ }^{*}$ to maximize $V\left(R_{r}\right)$, where

$$
\begin{aligned}
V\left(R_{r}\right)=\delta^{t} p_{r} y_{r}+\delta^{t+1} \sum_{j_{t+1}=1}^{J} \pi_{j_{t+1}} & \max _{0 \leqslant R_{s}-y_{s} \leqslant S^{*}} V\left[(1-\alpha)\left(R_{r}-y_{r}\right)+x_{j_{t+1}}\right]
\end{aligned}
$$

with $s=\left(r, j_{t+1}\right) \in \Omega_{t+1}$.

$V\left(R_{r}\right)$ is to be maximized subject to the constraint

$$
0 \leq R_{r}-y_{r} \leq S^{*}
$$

Thus at time $T$, with $R_{w}$ units of water available for release $\left(w=\left(j_{1}, \cdots, j_{T}\right) \in \Omega_{T}\right), y_{w}$ is chosen to $\max \delta^{T} p_{w} y_{w}$ subject to $0 \leq R_{w}-y_{w} \leq S^{*}$.

Given the linear increasing objective function together with the linear constraints, clearly the optimal policy involves setting $y_{w}^{*}=R_{w}$.

At $T-1$, with $R_{v}$ units of water available $\left(v=\left(j_{1}, \cdots\right.\right.$, $\left.\left.j_{T-1}\right) \in \Omega_{T-1}\right), y_{v}$ is chosen to

$\max V\left(R_{v}\right)=\max \delta^{T-1} p_{v} y_{v}$

$$
+\delta^{T} \sum_{j T=1}^{J} \pi_{j_{T}} p_{w}\left[(1-\alpha)\left(R_{v}-y_{v}\right)+x_{j_{T}}\right]
$$

subject to $0 \leq R_{v}-y_{v} \leq S^{*}$, where $w=\left(v, j_{T}\right) \in \Omega_{T}$.

Thus

$$
\frac{\partial V}{\partial y_{v}}=\delta^{T-1}\left[p_{v}-\delta(1-\alpha) \sum_{j \tau=1}^{J} \pi_{j T} p_{w}\right]
$$

The term inside the square brackets is the difference between the value at time $T-1$ of a unit of water released at $T-1$, and the discounted expected value at time $T-1$ of a unit of water stored at time $T-1$ for release at time $T$. The "own interest rate" $\gamma=\alpha /(1-\alpha)$ is included as a discount factor, with

$$
\delta(1-\alpha)=\left(\frac{1}{1+i}\right)\left(\frac{1}{1+\gamma}\right)
$$

When the term inside the square brackets is positive, the optimal release $y_{v}{ }^{*}=R_{v}$, the stock of water available. When the term is negative, $y_{v}{ }^{*}=\max \left\{0, R_{v}-S^{*}\right\}$, that is, as much water as possible is stored. When the term inside the square brackets is zero, then any feasible release is optimal.

In the general case of an arbitrary index $t$ and streamflow sequence indexed by $r \in \Omega_{t}$, the relevant criterion for the damreservoir operator is the expression

$\left[p_{r}-\max _{s} \sum_{j_{t+1}=1}^{J} \cdots \sum_{j_{t+s}=1}^{J} \delta^{s}(1-\alpha)^{s} \pi_{j_{t+1}} \cdots \pi_{j_{t+s}} p_{w_{s}}\right]$

where $s=1, \cdots, T-t$ and $w_{s}=\left(r, j_{t+1}, \cdots, j_{t+s}\right) \in \Omega_{t+s}$.

If (14) is positive, then it pays (in discounted expected profit terms) to release as much water as possible at time $t$; if it is negative, then there is a time in the future such that water released at that time has a higher discounted expected value today than water released today, so as much water as possible should be held in storage. If the expression is zero, any feasible release is optimal.
Using (14) to regulate releases determines the supply of water to be made available at any point in time for any given sequence of streamflows, and hence this determines the supply of contingent claims to water offered by the dam-reservoir operator as a function of the set of prices $p_{1}$, for contingent claims, and the storage capacity $S^{*}$.

Equilibrium in the market for contingent claims occurs when there is simultaneous clearing of all such markets, so that the price vector $(p, q)$ satisfies

$$
\begin{gathered}
\sum_{i=1}^{I} y_{s}{ }^{i}(p ; q)=y_{s}{ }^{*}\left(p, S^{*}\right) \quad s \in \Omega \\
\sum_{i=1}^{I} z_{s}{ }^{i}(p ; q)=\sum_{i=1}^{I} \frac{z}{r}^{i} \quad s \in \Omega
\end{gathered}
$$

Solving this system of $2(J \times T)$ simultaneous equations in $p$, $q$ for each value of $S, 0 \leq S \leq S^{*}$ would (in principle!) enable us to determine the values of the terms $\left(d p_{r} / d S\right)$ appearing in the expression (8) for consumer's surplus and hence to complete the formal calculation of that magnitude. We will not attempt that task here.

Under the appropriate assumptions, when total (consumer plus producer) surplus is maximized, then an ex ante Pareto optimum is achieved; that is, it is not possible to make one consumer better off in terms of expected utility without making some other consumer worse off. It should also be pointed out that expected utility calculations involve only the probabilities associated with streamflows, since this is the only source of randomness in our model of a water economy with a complete set of contingent claim markets. We next turn to the other extreme, an economy with no contingent claim markets but with spot markets open in each period.

\section{A Spot Market Water Economy}

In this section, we consider an economy with no contingent claim or futures markets but instead one with a complete set of spot markets, opening at each of the $T$ dates in the planning horizon. From the point of view of a typical consumer in this economy, there are now two sources of uncertainty, that is, uncertainty as to streamflows at various dates in time and uncertainty as to the prices that will prevail in future spot markets. To minimize notational clutter, we will assume that both kinds of uncertainty get incorporated into the consumer's subjective probability distribution over prices in future spot markets. That is, each consumer has a subjective probability distribution function (pdf) over the spot prices that will prevail at each point in time, which pdf reflects the underlying uncertainty as to streamflows and the behavior of other consumers; $p_{t}$ is now the price of good $y$ in period $t$ and $q_{t}$ is the price per unit of good $z$ in period $t$, both being random variables. The reservoir storage capacity $S$ then shows up as a parameter of the consumer's pdf over prices, where $f_{r}\left(p_{t}, \cdots, p_{T} ; q_{t}, \cdots, q_{T} ; S\right)$ is the (subjective) pdf at time $t$ over prices from time $t$ to $T$.

Once again we are interested in constructing a measure of the benefits to a consumer from the construction of a damreservoir complex with capacity $S^{*}$ to control streamflows. The decision problem for the consumer over a $T$ priced horizon is to choose consumption vectors $y=\left(y_{1}, \cdots, y_{T}\right)$ and $z=\left(z_{1}, \cdots, z_{T}\right)$ to maximize

$$
\begin{aligned}
E U=\sum_{t=1}^{T} \beta^{t} \int \cdots \int & U_{t}\left(y_{t}, z_{t}\right) \\
& \cdot f_{t}\left(p_{t}, \cdots, p_{T} ; q_{t}, \cdots, p_{T} ; S\right) d p d q
\end{aligned}
$$


subject to

$$
W(T)=\sum_{t=1}^{T}\left(M_{t}-p_{t} y_{t}-q_{t} z_{t}\right) /(1+i)^{t}=0
$$

In this formulation the (constant) one period interest rate $i$ is known with certainty. We assume a perfect capital market. Let

$$
\mathrm{DPV}=\sum_{t=1}^{T} M_{t} /(1+i)^{2}
$$

denote the discounted present value of income, and let

$M_{t}^{*}=\mathrm{DPV}-\sum_{s=1}^{t-1}\left(p_{s} y_{s}+q_{s} z_{s}\right) /(1+i)^{s} \quad t=1, \cdots, T$

denote the net amount of DPV available to be spent from time $t$ on. A basic problem with a sequential consumption model such as this one is the default problem. Here we simply make the (heroic) assumption that default never occurs, i.e., $M_{t}^{*}$ is always positive. This avoids introducing a complicated budget constraint in which consumption is at a subsistence level if default ever occurs.

The consumer presumably adopts a dynamic programming approach to solving his decision problem. We illustrate for the case of a two-period horizon.

In the case where $T=2$, then at time 2 , when $p_{2}, q_{2}$, and $M_{2}{ }^{*}$ are known the consumer chooses $y_{2}$ and $z_{2}$ to

$$
\max U_{2}\left(y_{2}, z_{2}\right)
$$

subject to

$$
M_{2}^{*}=p_{2} y_{2}+q_{2} z_{2}
$$

Solving this problem, we obtain the demand functions

$$
\begin{aligned}
& y_{2}=y_{2}\left(p_{2}, q_{2}, M_{2}{ }^{*}\right) \\
& z_{2}=z_{2}\left(p_{2}, q_{2}, M_{2}{ }^{*}\right)
\end{aligned}
$$

Reverting to time 1 , the consumer chooses $y_{1}$ and $z_{1}$ to maximize

$$
\begin{array}{r}
E U=\beta U_{1}\left(y_{1}, z_{1}\right)+\beta^{2} \iint U_{2}\left[y_{2}\left(p_{2}, q_{2}, M_{2}{ }^{*}\right),\right. \\
\left.z_{2}\left(p_{2}, q_{2}, M_{2}^{*}\right)\right] f\left(p_{2}, q_{2}, S\right) d p_{2} d q_{2}
\end{array}
$$

First-order conditions characterizing an (unconstrained) maximum are given by

$$
\begin{aligned}
& \frac{\partial E U}{\partial y_{1}}=\beta \frac{\partial U_{1}}{\partial y_{1}}+\beta^{2} \frac{\partial E U_{2}}{\partial y \cdot}=0 \\
& \frac{\partial E U}{\partial z_{1}}=\beta \frac{\partial U_{1}}{\partial z_{1}}+\beta^{2} \frac{\partial E U_{2}}{\partial z_{1}}=0
\end{aligned}
$$

Given this framework, how much is the consumer willing to pay (in terms of DPV) for an inceease $d S$ in the storage capacity of the reservoir? Since the consumer is to be indifferent between a situation with a storage capacity of $S$ and one with a storage capacity of $S+d S$, we have

$$
d E U=0
$$

where $E U=E U\left(p_{1}, q_{1}, y_{1}, z_{1}, \mathrm{DPV}, S\right)$, since $M_{2}{ }^{*}=M_{2}{ }^{*}\left(p_{1}\right.$, $\left.q_{1}, y_{1}, z_{1}, \mathrm{DPV}\right)$.

Hence we have

$$
d E U=\frac{\partial E U}{\partial y_{1}} \frac{d y_{1}}{d S}+\frac{\partial E U}{\partial z_{1}} \frac{d z_{1}}{d S}+\frac{\partial E U}{\partial q_{1}} \frac{d q_{1}}{d S}
$$

$$
+\frac{\partial E U}{\partial p_{1}} \frac{d p_{1}}{d S}+\frac{\partial E U}{\partial S} d S+\frac{\partial E U}{\partial \mathrm{DPV}} d \mathrm{DPV}=0
$$

From the first-order conditions, $\partial E U / \partial y_{1}=\partial E U / \partial z_{1}=0$. By the usual partial equilibrium assumption, $d q_{1} / d S=0$. Also note that

$$
\frac{\partial E U}{\partial p_{1}}=\beta^{2} \frac{\partial E U}{\partial M_{2}^{*}}\left(\frac{-y_{1}}{1+i}\right)
$$

while

$$
\frac{\partial E U}{\partial \mathrm{DPV}}=\beta^{2} \frac{\partial E U_{2}}{\partial M_{2}{ }^{*}}
$$

where

$$
\frac{\partial E U_{2}}{\partial M_{2}{ }^{*}}=\iint\left[\frac{\partial U_{2}}{\partial y_{2}}\left(\frac{\partial y_{2}}{\partial M_{2}{ }^{*}}+\frac{\partial U_{2}}{\partial z_{2}}\right) \frac{\partial z_{2}}{\partial M_{2}{ }^{*}}\right] f\left(p_{2}, q_{2}, S\right) d p_{2} d q_{2}
$$

Hence we obtain

$$
\begin{aligned}
d \mathrm{DPV}= & \left(\frac{1}{1+i}\right) y_{1}\left(\frac{d p_{1}}{d S}\right) d S \\
& -\left[(\partial E U / \partial S) /\left(\partial E U_{2} / \partial M_{2}^{*}\right)\right] d S
\end{aligned}
$$

where

$$
\frac{\partial E U}{\partial S}=\int_{0}^{\infty} \int_{0}^{\infty} U_{2}\left(y_{2}, z_{2}\right) \frac{\partial f}{\partial S}\left(p_{2}, q_{2}, S\right) d p_{2} d q_{2} \equiv \partial E U_{2} / \partial S
$$

Given a change from an uncontrolled river $(S=0)$ to a river with a dam-reservoir complex with reservoir storage capacity of $S^{*}$ units, the relevant consumer surplus measure in a spot market economy is given by

$$
\begin{aligned}
\mathrm{CS} & =\left|\operatorname{DPV}\left(S=S^{*}\right)-\operatorname{DPV}(S=0)\right| \\
& =-\left(\frac{1}{1+i}\right) \int_{0}^{S *} y_{1}{ }^{c}\left(\frac{d p_{1}}{d S}\right) d S+\int_{0}^{S *}\left(\frac{\partial E U_{2} / \partial S}{\partial E U_{2} / \partial M_{2}{ }^{*}}\right) d S
\end{aligned}
$$

Here again $y_{1}{ }^{c}$ is the compensated demand curve for $y_{1}$.

Two things should be noted about this measure of consumer surplus as contrasted to that for the case of the contingent claim economy. First, only the first-period compensated demand curve appears in the CS measure; benefits in the second period are already incorporated into the first-period demand curve through the dynamic programming algorithm. Second, the CS measure includes a term that is nonobservable, representing the benefits that accrue to the consumer from the change in $S$, when $p_{1}, y_{1}$ and $z_{1}$ remain unchanged. A less variable time stream of releases increases expected utility of second period consumption, even when first period consumptions (and prices) are unaffected. Since $\partial E U_{2} / \partial S \geq 0$ and $\partial E U_{2} / \partial M_{2}{ }^{*}>0$, using the first integral on the right in (28) to measure the benefits from the dam-reservoir complex understates the value of such benefits. Since the market (compensated) demand curve does not reveal the information contained in the second term of (28), there is a need for supplementary work by the cost-benefit analyst, designed to elicit information as to the properties of the underlying $E U$ function. (It has been pointed out that the compensated demand curve itself is unobserved, so that in practice cost-benefit studies use the area under the ordinary demand curve as a proxy for the true consumer surplus area. Willig [1976] has shown that under relatively weak conditions, the error involved in using the observed ordinary demand curve in consumer surplus calculations is minor. It is not clear how a proxy could be constructed to estimate the unobserved area identified in (28). 
One possible approach would be to estimate the error involved in ignoring the second term in (28) by using, say, a constant coefficient of risk aversion utility function with a normal approximation to the density. This has not been attempted by this author.)

The extension to the $T$ period case is straightforward. Define $H_{t}\left(y_{t}, z_{t}, M_{t}^{*}\right)$ by

$$
\begin{aligned}
H_{t}\left(y_{t}, z_{t}, M_{t}^{*}\right)= & U_{t}\left(y_{t}, z_{t}\right) \\
& +\beta E\left[\max _{y_{t+1}, z_{t+1}} H_{t+1}\left(y_{t+1}, z_{t+1}, M_{t+1}{ }^{*}\right)\right]
\end{aligned}
$$

where

$$
M_{t+1}^{*}=M_{t}^{*}-\left(p_{t} y_{t}+q_{t} z_{t}\right) /(1+i)^{t}
$$

Then at any time $t, t=1, \cdots, T$, the consumer chooses $y_{t}, z_{t}$ to maximize $H_{t}$. By an inductive argument it can be shown that this leads to the derivation of the demand functions

$$
\begin{aligned}
& y_{t}=y_{t}\left(p_{t}, q_{t}, M_{t}^{*}, S\right) \\
& z_{t}=z_{t}\left(p_{t}, q_{t}, M_{t}^{*}, S\right)
\end{aligned}
$$

$t=2, \cdots, T$.

Hence at time 1 , the consumer chooses $y_{1}$ and $z_{1}$ to maximize $E U$, where $E U$ is given by

$$
\begin{aligned}
E U=\beta U\left(y_{1}, z_{1}\right)+ & \sum_{t=2}^{T} \beta^{t} E U_{t} \\
& \cdot\left[y_{t}\left(p_{t}, q_{t}, M_{t}^{*}, S\right), z_{t}\left(p_{t}, q_{t}, M_{t}^{*}, S\right)\right]
\end{aligned}
$$

First-order conditions are given by

$$
\begin{aligned}
& \frac{\partial E U}{\partial y_{1}}=\beta \frac{\partial U}{\partial y_{1}}+p_{1} \sum_{t=2}^{T} \beta^{t} \frac{\partial E U_{t}}{\partial M_{t}^{*}}=0 \\
& \frac{\partial E U}{\partial z_{1}}=\beta \frac{\partial U}{\partial z_{1}}+q_{1} \sum_{t=2}^{T} \beta^{t} \frac{\partial E U_{t}}{\partial M_{t}^{*}}=0
\end{aligned}
$$

Consider now the derivation of a consumer surplus measure. $E U=E U\left(y_{1}, z_{1}, p_{1}, q_{1}\right.$, DPV, $\left.S\right)$ so that under the partial equilibrium assumption, again we have

$$
d \mathrm{DPV}=-\left[\frac{\left(\partial E U / \partial p_{1}\right)}{(\partial E U / \partial \mathrm{DPV})}\left(\frac{d p_{1}}{d S}\right)-\frac{(\partial E U / \partial S)}{(\partial E U / \partial \mathrm{DPV})}\right] d S
$$

where

$$
\begin{gathered}
\frac{\partial E U}{\partial p_{1}}=-\left(\frac{y_{1}{ }^{c}}{1+i}\right) \sum_{t=2}^{T} \beta^{t} \frac{\partial E U_{t}}{\partial M_{t}^{*}} \\
\frac{\partial E U}{\partial \mathrm{DPV}}=\sum_{t=2}^{T} \beta^{t} \frac{\partial E U_{t}}{\partial M_{t}^{*}}
\end{gathered}
$$

Hence the consumer surplus measure for consumer $i$, for the evaluation of the benefits from increasing $S$ from 0 to $S^{*}$ is again given by

$$
\begin{aligned}
\mathrm{CS} & =\left|\operatorname{DPV}\left(S=S^{*}\right)-\operatorname{DPV}(S=0)\right| \\
& =-\left(\frac{1}{1+i}\right) \int_{0}^{S *} y_{1}^{c}\left(\frac{d p_{1}}{d S}\right) d S+\int_{0}^{S *} \frac{(\partial E U / \partial S)}{(\partial E U / \partial \mathrm{DPV})} d S
\end{aligned}
$$

While the expression for $\partial E U / \partial S$ is considerably more complicated in this case than in the two-period case, still $\partial E U / \partial S \geq 0$, so that if the area under the compensated $y_{1}{ }^{c}$ demand curve is used as a measure of consumer surplus, this understates the value of the benefits derived from the damreservoir project.

On the supply side the introduction of uncertainty as to future spot market prices does not raise any new conceptual problems, since the decision problem for the dam-reservoir operator is one of dynamic programming even when price uncertainty is absent. Given an expected income maximizing operator, the effect of introducing price uncertainty is simply that of replacing the known prices $p_{r}$ of contingent claims associated with the streamflow sequence $x(r)$, with the expected value $E p_{r}$ of the uncertain spot market price, in the operator's criterion function. That is, the rule for the operator is based on the expression

$$
\left[p_{r}-\max _{s} \sum_{j_{t+1}=1}^{J} \cdots \sum_{j_{t+s}=1}^{J} \delta^{s}(1-\alpha)^{s} \pi_{j_{t+1}} \cdots \pi_{j_{t+s}} E p_{w_{s}}\right]
$$

where $s=1, \cdots, T-t$ and $w_{s}=\left(r, j_{t+1}, \cdots, j_{t+s}\right) \in \Omega_{t+s}$.

If the term inside the brackets is positive, the operator should empty the reservoir at time $t$, releasing as much water as he can; if it is negative, then as much water as possible is stored; and if the expression is zero, any feasible release is consistent with a maximum of expected profits.

Equilibrium in the spot market for water in period $t$, given that the streamflow sequence $x(r)$ has occurred, is given by the conditions

$$
\begin{gathered}
\sum_{i=1}^{I} y_{t}^{i}\left(p_{t}, q_{t}, M_{t}^{*}, S\right)=y_{r}^{*}\left(p_{r}, q_{r}, S\right) \\
\sum_{i=1}^{I} z_{t}^{i}\left(p_{t}, q_{r} . M_{t}^{*}, S\right)=\sum_{i=1}^{I} z_{r}^{i}
\end{gathered}
$$

where $y_{t}{ }^{i}$ is the demand for water by consumer $i$ in period $t, z_{t}{ }^{i}$ is demand for other goods by consumer $i$ in period $t$, and $y_{r}{ }^{*}$ is releases by the dam-reservoir operator in period $t$, given the streamflow sequence $x(r), r \in \Omega_{t}$.

Once again, in principle, the system represented by (36) could be solved to obtain the appropriate equilibrium spot prices and in particular, a rational expectations equilibrium might be of interest to explore. (It should be emphasized that the system represented by (36) and (37) is quite a different system than that represented by the equilibrium conditions (15) and (16). Technically, the economy described by (36) and (37) is a sequential economy, with equilibrium prices revealed only after the random events (streamflows, market decisions) have occurred. In contrast, equilibrium prices satisfying (15) and (16) are those that arise in the time 0 contingent claim markets, and hence these prices are known before any random events take place. Given nondegenerate pdf's, the only situation in which the two systems become formally equivalent is when spot markets exist at times $1, \cdots, T$, but contingent claim contracts exist which specify payoffs based not only on the occurrence of streamflows but also on the basis of sequences of spot price vectors, one such claim for each possible combination of streamflow and spot price vector sequences. Clearly, this would require a continuum on contingent claim contracts and markets. In this case, the equilibrium conditions for the sequential economy would reduce to those given by (15) and (16). However, because the storage level $S$ still appears as a parameter of the consumer's pdf over spot prices, there would continue to be an unobserved term in the consumer surplus measure in this case.)

\section{EXAMPLE}

To illustrate, consider the case where $U_{t}=y_{t} z_{t}, t=1,2$, with

$$
f\left(p_{2}, q_{2}, S\right)=\frac{S+1}{S+2} \quad 1 \leq q_{2} \leq 2 \quad 1 \leq p_{2} \leq \frac{2 S+3}{S+1}
$$


Then it is easy to verify that

$$
y_{2}=M_{2}^{*} / 2 p_{2} \quad z_{2}=M_{2}^{*} / 2 q_{2}
$$

so that

$$
\begin{array}{r}
E U=y_{1} z_{1}+\beta \int_{1}^{2} \int_{1}^{2 S+3}\left(\frac{1}{S+1}\right) \frac{S+1}{S+2} \\
\cdot \frac{\left(\mathrm{DPV}-p_{1} y_{1}-q_{1} z_{1}\right)^{2}}{4 p_{2} q_{2}} d p_{2} d q_{2}
\end{array}
$$

Hence

$$
E U=y_{1} z_{1}+K\left(\mathrm{DPV}-p_{1} y_{1}-q_{1} z_{1}\right)^{2}
$$

where

$$
K=\frac{B}{4} \frac{S+1}{S+2} \ln \frac{(2 S+3)}{S+1} \ln 2
$$

Thus

$$
\begin{aligned}
& y_{1}=\frac{K q_{1}(\mathrm{DPV})}{1+2 p_{1} q_{1}} \\
& z_{1}=\frac{K p_{1}(\mathrm{DPV})}{1+2 p_{1} q_{1}}
\end{aligned}
$$

are the ordinary demand curves, and the compensated demand function for $y_{1}, y_{1}{ }^{c}$, with $E U=E \bar{U}$, is given by

$$
\begin{aligned}
y_{1}{ }^{c}=\left\{K \mathrm{DPV} p_{1}+\left[K^{2} p_{1}{ }^{2} \mathrm{DPV}^{2}-\left(K \mathrm{DPV}{ }^{2}-E \bar{U}\right)\left(4 K p_{1}{ }^{2}\right.\right.\right. \\
\left.\left.\left.+p_{1} / q_{1}\right)\right]^{1 / 2}\right\}\left(4 K p_{1}{ }^{2}+p_{1} / q_{1}\right)^{-1}
\end{aligned}
$$

Note that

$$
\frac{\partial E U_{2}}{\partial S}=\frac{\left(M_{2}{ }^{*}\right)^{2}}{4} \frac{(\ln 2)}{(S+2)^{2}}\left[\ln \frac{2 S+3}{S+1}-\frac{1}{(2 S+3)}\right]>0
$$

while $\partial E U_{2} / \partial M^{*}=2 E U_{2} / M^{*}>0$.

\section{SUMmaRY AND COMMENTS}

We have examined the construction of consumer surplus measures appropriate to the evaluation of a water project in two different economic environments: (1) an economy containing a complete set of contingent claim markets (and with no spot markets), and (2) an economy with a complete set of spot markets (but no contingent claim markets). In the ArrowDebreu type world, the consumer surplus measure that applies under uncertainty as to streamflows is of the same form as the measure that would apply under certainty, being the sum of the discounted consumer surplus areas for each period. The only difference between the certainty and uncertainty cases is that under uncertainty there is a consumer surplus area for each possible state of the world (sequence of streamflows) for each period.

Things are quite different in the case of a spot market economy. In the first place, only the consumer surplus area for first-period compensated demand appears in the consumer surplus measure; the dynamic programming approach implies that all of the benefits over the $T$ period horizon are captured in the first-period compensated demand function. But of more interest is the fact that the "correct" measure of consumer surplus includes an unobserved term, measuring the benefits accruing to the consumer from the change in expected utility due to a shift in the pdf over future spot prices, given unchanged first-period prices and consumptions.

The unobserved term in the CS measure raises some basic questions about the welfare implications of a CS measure de- signed to express the benefits accruing from a project such as a dam-reservoir complex, when the effect (in part) of the project is to alter the probability distributions of consumers over future spot prices. This is related to what is involved in the notion of an ex ante Pareto optimum. The idea is this. Ex ante optimality refers to any feasible allocation that maximizes the expected utility of one consumer for given levels of expected utility for other consumers; alternatively, at an ex ante optimum, we cannot make one consumer better off in terms of expected utility without making some other consumer worse off in terms of expected utility. But this is to hold for given subjective probability distributions over payoffs. If pdfs change, then any resulting allocation is simply non comparable (in the ex ante sense) with allocations holding before the change in pdfs.

The CS measure in (34) measures the benefits to an individual resulting from a parameter change that alters his or her subjective pdf over future price vectors. While the CS measure in (34) is the measure relevant for decision making with respect to a proposed dam-reservoir project, it is irrelevant to policy decisions linked to ex ante optimality or to the attainment of ex ante Pareto superior allocations because of the effect of the dam-reservoir project on the pdf's of consumers.

What is needed in the case of the spot market economy is a different notion of a Pareto ranking, one defined over vectors $\left(f^{1}, \cdots, f^{I}\right)$ of subjective pdfs, where the superscript refers to consumers. In this ranking, one vector is Pareto superior to another if the vector of expected utilities $\left(E U^{1}, \cdots, E U^{I}\right)$ associated with the first vector of pdf's is weakly larger (component by component) than the vector of expected utilities associated with the second vector of pdf's. A Pareto optimum is achieved with a feasible vector of pdf's if no other feasible vector of pdf's is Pareto superior to it. This is a completely different kind of Pareto ranking than the ex ante ranking, and presumably, it is this difference that in part at least accounts for the quite different specifications of CS as between (8) and (34), including the unobserved component in (34). As noted above, even if the sequential economy represented by equilibrium conditions (35) and (36) is reduced to a contingent claim economy, the unobserved component of consumer surplus still remains since $S$, the water storage level, is a parameter of the pdf over spot market prices.

Acknowledgments. I would like to thank an anonymous referee for his helpful suggestions concerning this paper, which represents an outgrowth of earlier work undertaken with the support of the Environmental Quality Laboratory at California Institute of Technology.

\section{REFERENCES}

Arrow, K., The role of securities in the optimal allocation of risk bearing, Rev. Econ. Stud., 31, 91-96, 1964.

Rogerson, W., Aggregate expected consumer surplus as a welfare index with an application to price stabilization, Rep. SSWP 205, Calif. Inst. of Technol., Pasadena, 19??.

Samuelson, P., The Foundations of Economic Analysis, Harvard University Press, Cambridge, Mass., 1947.

Willig, R., Consumer's surplus without apology?, Am. Econ. Rev., 66, 589-597, 1976.

J. Quirk, California Institute of Technology, Pasadena, CA 91125.

(Received January 24, 1985; revised March 12, 1985; accepted April 29, 1985.) 